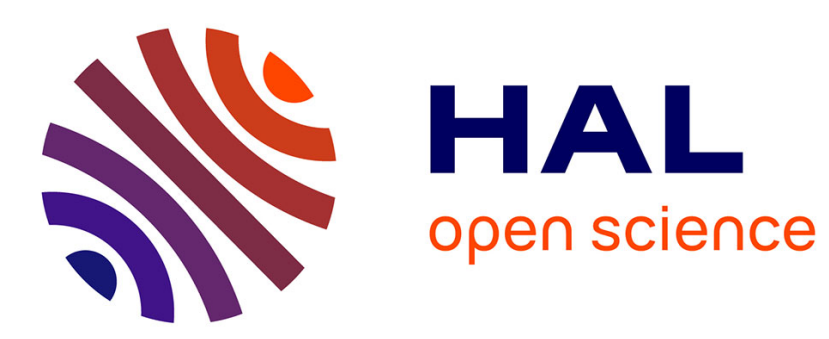

\title{
Magnetic resonance cholangiography: Current and future perspectives
}

Lionel Arrivé, Marianne Hodoul, Antoune Arbache, Lucie Slavikova-Boucher, Yves Menu, Sanaâ El Mouhadi

\section{- To cite this version:}

Lionel Arrivé, Marianne Hodoul, Antoune Arbache, Lucie Slavikova-Boucher, Yves Menu, et al.. Magnetic resonance cholangiography: Current and future perspectives. Clinics and Research in Hepatology and Gastroenterology, 2015, 39 (6), pp.659-664. 10.1016/j.clinre.2015.07.005 . hal-01188797

\section{HAL Id: hal-01188797 \\ https://hal.sorbonne-universite.fr/hal-01188797}

Submitted on 31 Aug 2015

HAL is a multi-disciplinary open access archive for the deposit and dissemination of scientific research documents, whether they are published or not. The documents may come from teaching and research institutions in France or abroad, or from public or private research centers.
L'archive ouverte pluridisciplinaire HAL, est destinée au dépôt et à la diffusion de documents scientifiques de niveau recherche, publiés ou non, émanant des établissements d'enseignement et de recherche français ou étrangers, des laboratoires publics ou privés. 
Magnetic resonance cholangiography: Current and future perspectives

Lionel Arrivé, Marianne Hodoul, Antoune Arbache, Lucie Slavikova-Boucher, Yves Menu, Sanaâ El Mouhadi

Department of Radiology, Sorbonne Universités, UPMC Univ. Paris 06, Saint-Antoine Hospital, Assistance publique-Hôpitaux de Paris

Corresponding author: Lionel Arrivé

Department of Radiology

Saint-Antoine Hospital

184 Rue du Faubourg Saint-Antoine

75012 Paris

lionel.arrive@sat.aphp.fr

Phone: +33149282258

Fax: +33149282259 
Magnetic resonance cholangiography (MRC) has become the standard of reference for imaging of the biliary ducts. The use of three dimensional (3D) sequences has resulted in improved spatial resolution with virtually isotropic voxel and improved signal/noise ratio. In addition to MRC images, 3D fat suppressed T1-weighted MR images should be systematically obtained to search for intrahepatic calculi.

MRC plays a major role in the diagnosis of cholangiocarcinoma and assessment of its resectability. With modern MR systems the performance of MR is basically the same that of CT for evaluation of arterial and portal vein extent. MRC is a key imaging modality for the diagnosis of primary sclerosing cholangitis. Different imaging patterns may be observed including multifocal intra and extrahepatic strictures alternating with slightly dilated ducts. Focal signal abnormality of the liver parenchyma and focal parenchymal atrophy represent the consequences of biliary duct obstruction on liver parenchyma. Diagnosis of biliary lithiasis is performed by combination of MRC and T1-weighted MR imaging. MRC can be performed for the diagnosis of secondary cholangitis including ascending cholangitis, ischemic cholangitis and IgG4-related sclerosing cholangitis.

Hepatobiliary contrast agents could be used for demonstrating the site of biliary duct leakage after surgery and for functional imaging. MR imaging can also be used to determine the prognosis of PSC. The inherent limitations of MRC of bile ducts are still the suboptimal spatial resolution for evaluation of distal intrahepatic biliary ducts. 
Magnetic resonance cholangiography

Magnetic resonance cholangiography (MRC) has become the standard of reference as a technique for morphologically examining the biliary ducts. Endoscopic retrograde cholangiography (ERCP) was long considered the reference technique for diagnosing biliary duct diseases. However, ERCP is an invasive procedure associated with a risk of major complications, including pancreatitis, biliary sepsis, bleeding and perforation, and is no longer performed for diagnostic purposes. Ultrasound remains a sensitive examination for detecting intrahepatic calculi.,There are virtually no indications for computed tomography. Several papers have demonstrated the extremely high diagnostic accuracy of MRC in the detection of biliary duct stones and benign biliary strictures, as well as malignant lesions of the biliary tree $(1,2)$.

\section{$\underline{\text { MRC }}$}

MRC with very heavily T2-weighted sequences exploits the combination of the high signal intensity of static fluids in the biliary tract and the low signal intensity of background tissues. MRC can be performed with both two-dimensional (2D) and three-dimensional (3D) sequences. When the first magnetic resonance cholangiography images were obtained in the beginning of the 1990s with the possibility of using fast spin echo sequences and simultaneous reading of several lines of the Fourier plane, they were the result of twodimensional (2D) acquisitions (3). The principal advantage of these 2D sequences was a short acquisition time feasible within a single breath-hold, indicating that they are not very sensitive to motion artifacts. Furthermore, these 2D sequences do not require post-processing and can be interpreted immediately (4). However, these 2D sequences are associated with the risk of a partial volume effect because, by nature, the acquisition only concerns one slice plane.

\section{3-D MRC}

The use of three-dimensional (3D) sequences has resulted in significant advances in diagnostic performance. The main advantage of 3D isotropic MRCP is the use of thinner section source images, resulting in a virtually isotropic voxel, providing high resolution in all three spatial planes with an excellent signal/noise ratio, which allows optimal post-processing of image data to obtain maximum intensity projection (MIP) images and multiplanar reformatted (MPR) images. Therefore, 3D MRC combines the advantages of projectional 
imaging with those of cross-sectional imaging. MIP global 3D images provide a spatial overview of the biliary tract anatomy, while thin or thick MPR images help visualize small abnormalities such as stones. However, it should be stressed that one should always analyze the thin section source images, and not rely exclusively on post-processed images (5).

With modern machines, 3D MRC seems to be clearly superior to 2D MRC, the only advantage of which is the ability to make dynamic acquisitions, which are only infrequently needed (6). In the majority of cases, 3D MRC is performed using native images acquired in the coronal plane.

\section{Complementary sequences}

MR imaging of biliary diseases is not restricted to MRC (7). Unlike T2-weighted sequences, which can be considered optional if the magnetic resonance cholangiography study is of good quality, the T1-weighted sequence is absolutely essential for assessing biliary diseases when searching for intrahepatic calculi. Indeed, the majority of intrahepatic calculi produce T1weighted hyperintensity, likely due to the presence of hemoglobin degradation products. It is recommended that $\mathrm{T} 1$-weighted sequences obtained during $3 \mathrm{D}$ acquisition with fat saturation be used to suppress the fat signal intensity present within the hilum of the liver.

Contrast agents are not strictly mandatory during biliary duct MR imaging. However, intravenous injection of a gadolinium chelate is currently used in patients with biliary neoplastic obstruction (8). In addition, negative oral contrast agents can be usefully employed to reduce the brightness of the gastric and intestinal fluids in order to enhance the visualization of the biliary tree and pancreatic ducts (9). At our institution, we use the ingestion of pineapple juice, which is very effective for reducing the signal from digestive structures on T2-weighted images because of the high concentration of manganese, which decreases the signal intensity of the fluid contained within the small bowel (10).

\section{$\underline{\text { Biliary diseases }}$}

\section{Cholangiocarcinoma}

MR imaging plays a major role in the diagnosis of cholangiocarcinoma and the assessment of its resectability (Figure 1). Contrast-enhanced MR imaging with MR cholangiography is particularly useful to accurately assess the extent of ductal involvement (11). MRC can accurately evaluate the site of the obstruction and the nature of the stricture. Malignant strictures usually appear as marked irregular strictures with significant proximal bile duct 
dilatation. Localized hepatic parenchymal atrophy is commonly observed in combination with biliary duct dilatation (12). Presently, CT scanning is still commonly performed to evaluate the extent of arterial and portal venous invasion. However, with modern MR systems, the performance of MR is basically the same as that of CT. In addition, MRC can be valuable in the evaluation of and therapeutic planning for patients with biliary-enteric anastomoses (13, 14).

Primary sclerosing cholangitis

Primary sclerosing cholangitis (PSC) is a rare chronic cholestatic liver disease with an incidence rate of 0.77 per 100,000 person-years (15-17). Although the natural course may vary from one patient to another, PSC is often progressive, leading to biliary cirrhosis and its complications. A diagnosis of PSC is made in patients with cholestasis that is not otherwise explained, when MRC shows multifocal strictures and segmental dilatations and when possible causes of secondary sclerosing cholangitis (especially IgG4-associated cholangitis) have been excluded (18).

The features on MRC include multifocal intra- and extrahepatic bile ducts with moderate or severe strictures alternating with slightly dilated ducts. The MRC findings in patients with PSC are markedly variable. Different imaging patterns may be observed, probably related to the stage of the disease process and to the pattern of disease. Early in the course of the disease, randomly distributed, short, diffuse intrahepatic strictures alternating with normal or slightly dilated segments are observed. Contrast-enhanced T1-weighted images may demonstrate biliary wall thickening and mural contrast enhancement of the biliary ducts related to the inflammatory process (Figure 2). As the fibrosing process worsens, the strictures increase and the ducts become obliterated. Focal signal abnormalities of the liver parenchyma on T2- and diffusion-weighted images suggesting cholestasis, inflammation and fibrosis are observed. Consequently, focal parenchymal atrophy is observed (Figure 3). However, the natural history of PSC is complex (19). The disease may remain stable with minimal biliary abnormalities over a period of years, or may show rapid worsening of biliary stenoses with marked parenchymal abnormalities. Other MRC features include webs, diverticula and stones (20). A web is a focal, 1-2 mm-thick area of incomplete circumferential narrowing; a diverticulum is a focal saccular dilatation of the bile duct. Such diverticula are now easily demonstrated with MRC. Primary pigmented stones secondary to bile stasis are demonstrated as focal areas of high signal intensity. Cholangiocarcinoma occurs in $10 \%-15 \%$ of patients 
with PSC and has a poor prognosis. The tumor is usually located in the common hepatic duct or at the bifurcation. The MRC features that suggest malignant degeneration include the rapid progression of strictures and marked ductal dilatation proximal to strictures. However, a diagnosis of cholangiocarcinoma associated with PSC is difficult, as the inflammatory process may simulate cholangiocarcinoma (21).

\section{Biliary lithiasis}

The accuracy of MRC in the evaluation of bile duct stones is high (22). Stones appear as dark filling defects of variable shape within the biliary tree or gallbladder. An evaluation of thin section source images is mandatory. Possible pitfalls include air bubbles, blood clots or hypertrophy of the sphincter of Oddi that mimics biliary duct stones (23). However, high signal intensity is observed on T1-weighted MR images in biliary duct stones and allows a definite diagnosis (24-26).

\section{Secondary cholangitis}

Secondary sclerosing cholangitis has imaging features similar to those of PSC; however, this syndrome refers to sclerosing cholangitis that results from a known pathological process or injury (Table 1). Ascending cholangitis is related to bacterial contamination of the biliary system, usually with Gram-negative enteric bacteria. Bile duct strictures, stones and papillary stenosis are the most common causes of ascending cholangitis. Biliary obstruction causes biliary stasis and suppurative cholangitis. Liver abscesses and sepsis can occur when necrosis of the bile duct wall occurs. The role of MRC is to demonstrate the cause of bile duct obstruction. The main MRC features of ascending cholangitis are bile ducts strictures, which are commonly localized in continuation with stones and biliary abscesses (27).

Ischemia-induced biliary ducts lesions are recognized as ischemic cholangitis. Injury of the biliary epithelium occurs when the arterial supply is altered at either the level of the main hepatic artery or at the peribiliary capillary plexus. The MRC findings include multifocal bile ducts lesions. The predominant site of involvement is the confluence of intrahepatic ducts (28). Hyperintensity on T1-weighted MR images, the so-called "cast syndrome", which is related to necrosis of the epithelium, is frequently observed (29). After liver transplantation, bile duct strictures may occur because of iatrogenic injury, hepatic arterial thrombosis or stenosis, or chronic rejection. Ischemic injury can also occur after injury to the vascular supply during biliary or pancreatic surgery. Hepatic arterial infusion of chemotherapeutic agents has also been demonstrated to be a cause of ischemic cholangitis. 
IgG4-related sclerosing cholangitis is commonly associated with autoimmune pancreatitis (present in up to $80 \%$ of cases) and other IgG4 related diseases (30). Both intrahepatic and extrahepatic bile ducts can be involved, with the lower common bile duct being the most common area of involvement. Multifocal intrahepatic or upper extrahepatic bile duct strictures or bile duct thickening mimicking PSC may be present (Figure 4a). Therefore, differential diagnosis with PSC is difficult (16). Significant improvement is observed with corticosteroids (Figure 4b). The main MRC features of IgG4-related sclerosing cholangitis are multifocal central bile duct strictures, which are frequently associated with main pancreatic duct involvement (31).

\section{Perspectives}

There is increasing interest in the use of hepatobiliary contrast agents, such as mangafodipir trisodium (Teslascan, Nycomed, Oslo, Norway), gadoxetic disodium acid (Primovist, Schering co., Berlin, Germany) or gadobenate dimeglumine (MultiHance, Bracco, Milan, Italy) (32). These agents, which are administered intravenously, are excreted primarily through the biliary system. The direct visualization of the biliary tree using these contrast agents allows for a functional evaluation. Presently, such contrast media are mainly used in cases of post-surgery biliary duct leakage to demonstrate the site of leak (33). However, such contrast media could also be used for functional imaging (32).

At present, sub-segmental intrahepatic ducts are still sub-optimally demonstrated on MRC. Therefore, several authors have proposed the administration of pharmacological agents to contract the sphincter of Oddi to increase the pressure and distention of the biliary and pancreatic ducts to improve biliary duct visualization. The use of morphine or fentanyl, both of which can produce contraction of the sphincter of Oddi, has been proposed $(34,35)$. Similarly, secretin has been proposed to stimulate pancreatic fluid secretion and increase the tone of the sphincter of Oddi to produce a mild dilation of the main and secondary ducts (36, $37)$.

As noted above, PSC has a markedly variable evolution. In some cases, the biliary disease remains stable over several years, with minimal or moderate biliary abnormalities. On the other hand, rapid and marked worsening of biliary stenoses with hepatic parenchymal alterations and secondary biliary cirrhosis with portal hypertension may be observed in other 
patients. Recently, Ruiz et al. proposed two simple radiological scores, the so-called ANALI scores (depending on gadolinium administration) that provided accurate information on the risk of radiological progression. These are two MRI progression risk scores, based on the combination of predictive radiological features (the score without gadolinium administration $=1 \mathrm{x}$ dilatation of intrahepatic bile ducts $+2 \mathrm{x}$ dysmorphy $+1 \mathrm{x}$ portal hypertension and the score with gadolinium administration $=1 \mathrm{x}$ dysmorphy $+1 \mathrm{x}$ parenchymal enhancement heterogeneity). These scores were associated with radiological progression, with an area under the curve of 80 and $83 \%+/-4 \%$ (38).

The recent improvements in both contrast and spatial resolution allow the evaluation of the arterial and portal vessels with performance comparable to that of a CT scan. An accurate evaluation of both the hepatic artery and portal vein is mandatory to analyze the involvement of vascular structures, especially in cases of cholangiocarcinoma. Therefore, it is likely that MR imaging with MRC will become a "one-stop-shop" for the diagnosis and evaluation of cholangiocarcinoma.

At present, MRC is not commonly performed before laparoscopic cholecystectomy. However, in view of the uncommon, but potentially dramatic, complications related to surgery-induced biliary duct injury, MRC could be performed to depict biliary anatomical variations, which may make a patient prone to surgical complications (39) (Figure 5). However, costeffectiveness of such diagnostic procedure should be evaluated

\section{Conclusion}

The inherent limitations of MRI and MRC of the bile ducts are still the suboptimal spatial resolution. A precise examination of the distal bile ducts is still not possible and is the last remaining limitation of MRC. In the next few years, the role of MRC will further expand due to the availability of faster sequences, 3D imaging, specific contrast agents and functional studies. Finally, the recent introduction of 3 Tesla magnets will likely provide an increased spatial resolution, further improving the performance of MRC. 
References

1. Motohara T, Semelka RC, Bader TR. MR cholangiopancreatography. Radiol Clin North Am 2003;41:89-96.

2. Sahni VA, Mortele KJ. Magnetic resonance cholangiopancreatography: current use and future applications. Clin Gastroenterol Hepatol 2008;6:967-77.

3. Wallner BK, Schumacher KA, Weidenmaier W, Friedrich JM. Dilated biliary tract: evaluation with MR cholangiography with a T2-weighted contrast enhanced fast sequence. Radiology 1991;181:805-8.

4. Soto JA, Yucel EK, Barish MA, Siegenberg D, Ferrucci JT, Chuttani R. MR cholangiopancreatography after unsuccessful or incomplete ERCP. Radiology 1996;199:91-8.

5. Soto JA, Alvarez O, Lopera JE, Múnera F, Restrepo, JC, Correa G. Biliary obstruction: findings at MR cholangiography and cross-sectional MR imaging. RadioGraphics 2000;20:353-66.

6. Van Hoe L, Gryspeerdt S, Vanbeckevoort D, De Jaegere T, Van Steenbergen W, Dewandel P, et al. Normal Vaterian sphincter complex: evaluation of morphology and contractility with dynamic single-shot MR cholangiopancreatography. AJR Am J Roentgenol 1998;170:1497500.

7. Kim MJ, Mitchell DG, Ito K, Outwater EK. Biliary dilatation: differentiation of benign from malignant causes-value of adding conventional MR imaging to MR cholangiopancreatography. Radiology 2000;214:173-81.

8. Brink JA, Borrello JA. MR imaging of the biliary system. Magn Reson Imaging Clin N Am 1995;3:143-60.

9. Kato J, Kawamura Y, Watanabe T, Okada S, Cho K, Ishihara M. Examination of intragastrointestinal tract signal elimination in MRCP: combined use of T1-shortening positive contrast agent and single-shot fast inversion recovery. J Magn Reson Imaging 2001;13:738-43.

10. Arrivé L, Coudray C, Azizi L, Lewin M, Hoeffel C, Monnier-Cholley L, Lacombe C, Vautier S, Poupon J, Tubiana JM. Pineapple juice as a negative oral contrast agent in magnetic resonance cholangiopancreatography. J Radiol 2007;88:1689-94. 
11. Blechacz B, Gores GJ. Cholangiocarcinoma: advances in pathogenesis, diagnosis, and treatment. Hepatology 2008;48:308-21.

12. Fulcher AS, Turner MA. HASTE MR cholangiography in the evaluation of hilar cholangiocarcinoma. AJR Am J Roentgenol 1997;169:1501-5.

13. Hoeffel C, Azizi L, Lewin M, Laurent V, Aubé C, Arrivé L, Tubiana JM. Normal and pathologic features of the postoperative biliary tract at 3D MR cholangiopancreatography and MR imaging. RadioGraphics 2006;26:1603-20

14. Forbes A, Cotton PB. ERCP and sphincterotomy after Billroth II gastrectomy. Gut 1984;25:971-4.

15. Molodecky NA, Kareemi H, Parab R, Barkema HW, Quan H, Myers RP, Kaplan GG. Incidence of primary sclerosing cholangitis: a systematic review and meta-analysis. Hepatology 2011;53:1590-9.

16. Chapman RW, Fevery J, Kalloo A, Nagorney DM, Boberg KM, Shneider B, Gores GJ; American Association for the Study of Liver Diseases. Diagnosis and management of primary sclerosing cholangitis. Hepatology 2010;51:660-78.

17. Naess S, Shiryaev A, Hov JR, Franke A, Karlsen TH. Genetics in primary sclerosing cholangites. Clin Res Hepatol Gastroenterol 2012;34:325-33.

18. Vitellas KM, Keogan MT, Freed KS, Enns RA, Spritzer CE, Baillie JM, Nelson RC. Radiologic manifestations of sclerosing cholangitis with emphasis on MR cholangiopancreatography. RadioGraphics 2000;20:959-75.

19. Ponsioen CY, Vrouenraets SM, Prawirodirdjo W, Rajaram R, Rauws EA, Mulder CJ, Reitsma JB, et al. Natural history of primary sclerosing cholangitis and prognostic value of cholangiography in a Dutch population. Gut 2002;51:562-6.

20. Dave M, Elmunzer BJ, Dwamena BA, Higgins PD. Primary sclerosing cholangitis: metaanalysis of diagnostic performance of MR cholangiopancreatography. Radiology 2010;256:387-96.

21. MacCarty RL, LaRusso NF, May GR, Bender CE, Wiesner RH, King JE, Coffey RJ. Cholangiocarcinoma complicating primary sclerosing cholangitis: cholangiographic 
appearances. Radiology 1985;156:43-6.

22. Soto JA, Barish MA, Alvarez O, Medina S. Detection of choledocholithiasis with MR cholangiography: comparison of three-dimensional fast spin echo and single- and multisection half-Fourier rapid acquisition with relaxation enhancement sequences. Radiology 2000;215:737-45.

23. Demartines N, Eisner L, Schnabel K, Fried R, Zuber, M, Harder F. Evaluation of magnetic resonance cholangiography in the management of bile duct stones. Arch Surg 2000;135:14852.

24. Benzimra J, Derhy S, Rosmorduc O, Menu Y, Poupon R, Arrivé L. Hepatobiliary anomalies associated with ABCB4/MDR3 deficiency in adults: a pictorial essay. Insights Imaging 2013;4:331-8.

25. Arrivé 1. Differentiation of hepatolithiasis and intrahepatic pneumobilia. AJR 2014;203:W450

26. Vitek L, Carey MC. New pathophysiological concepts underlying pathogenis of pigment gallstones. Clin Res Hepatol Gastroenterol 201;36:122-9.

27. Azizi L, Raynal M, Cazejust J, Ruiz A, Menu Y, Arrivé L. MR imaging of sclerosing cholangites. Clin Res Hepatol Gastroenterol 2012;36:130-8.

28. Deltenre P, Valla DC. Ischemic cholangiopathy. Journal of Hepatology 2006;44:806-17.

29. Arrivé L. Detection of cast in biliary cast syndrome. Radiology 2013;266:366.

30. Bjornsson E, Chari ST, Smyrk TC, Lindor K. Immunoglobulin G4 associated cholangitis: description of an emerging clinical entity based on review of the literature. Hepatology 2007;45:1547-4.

31. Bodily KD, Takahashi N, Fletcher JG, et al. Autoimmune pancreatitis: pancreatic and extrapancreatic imaging findings. AJR 2009;192:431-7.

32. Vitellas KM, El-Dieb A, Vaswani K, Bennett WF, Fromkes J, Steinberg S, Bova JG. Detection of bile duct leaks using MR cholangiography with mangfodipir trisodium (Teslascan). J Comput Assist Tomogr 2001;25: 102-5.

33. Aduna M, Larena JA, Martín D, Martínez-Guereñu B, Aguirre I, Astigarraga E. Bile duct 
leaks after laparoscopic cholecystectomy: value of contrastenhanced MRCP. Abdom Imaging 2005;30:480-7.

34. Silva AC, Friese JL, Hara AK, Liu PT. MR cholangiopancreatography: improved ductal distention with intravenous morphine administration. RadioGraphics 2004;24:677-87.

35. Agarwal S, Nag P, Sikora S, Prasad TL, Kumar S, Gupta RK. Fentanyl-augmented MRCP. Abdom Imaging 2006;31:582-7.

36. Matos C, Metens T, Devière J, Nicaise N, Braudé P, Van Yperen G, Cremer M, Struyven J. Pancreatic duct: morphologic and functional evaluation with dynamic MR pancreatography after secretin stimulation. Radiology 1997;203:435-41.

37. Lee NJ, Kim KW, Kim TK, Kim MH, Kim SY, Park MS, Kim AY, Ha HK, Kim PN, Lee MG. Secretin-stimulated MRCP. Abdom Imaging 2006;31:575-81.

38. Ruiz A, Lemoinne S, Carrat F, Corpechot C, Chazouillères O, Arrivé L. Radiologic course of primary sclerosing cholangitis: assessment by three-dimensional magnetic resonance cholangiography and predictive features of progression. Hepatology 2014;59:242-50.

39. Arrivé L, Ruiz A, El Mouhadi S, Azizi L, Monnier-Cholley L, Menu Y. MRI of cholangitis: traps and tips. Diagn Interv Imaging 2013;94:757-70. 
Figure legends

Figure 1: Hilar cholangiocarcinoma. a) MRCP demonstrates the biliary duct dilatation, lower end of tumor (arrow) is well demonstrated. b) After gadolinium injection tumor lesion (arrow) is well seen in front of portal vein bifurcation.

Figure 2: Primary sclerosing cholangitis. In this inflammatory pattern only moderate stenoses are observed throughout the intrahepatic biliary ducts (a). After gadolinium enhancement peribiliary enhancement (arrows) is well demonstrated.

Figure 3: Primary sclerosing cholangitis. In this severe pattern multiple marked stenoses are observed. Marked atrophy of right lobe is observed on the MRCP (a) and T2-weighted MR images (b).

Figure 4: IgG4-related sclerosing cholangitis: multiple marked central stenoses are observed (a) which resolved after steroid therapy (b).

Figure 5: Different patterns of biliary leaks after cholecystectomy. a) Biliary leak fromanterior right biliary channel (arrow). b) Biliary leak from so-called Luschka channels (arrow) (B: biloma).

\section{Table 1}

Causes of secondary sclerosing cholangitis

Biliary lithiasis

Ascending cholangitis

Ischemic cholangitis

Intra-arterial chemotherapy

IgG4-associated cholangitis

Eosinophilic cholangitis

Histiocytosis 


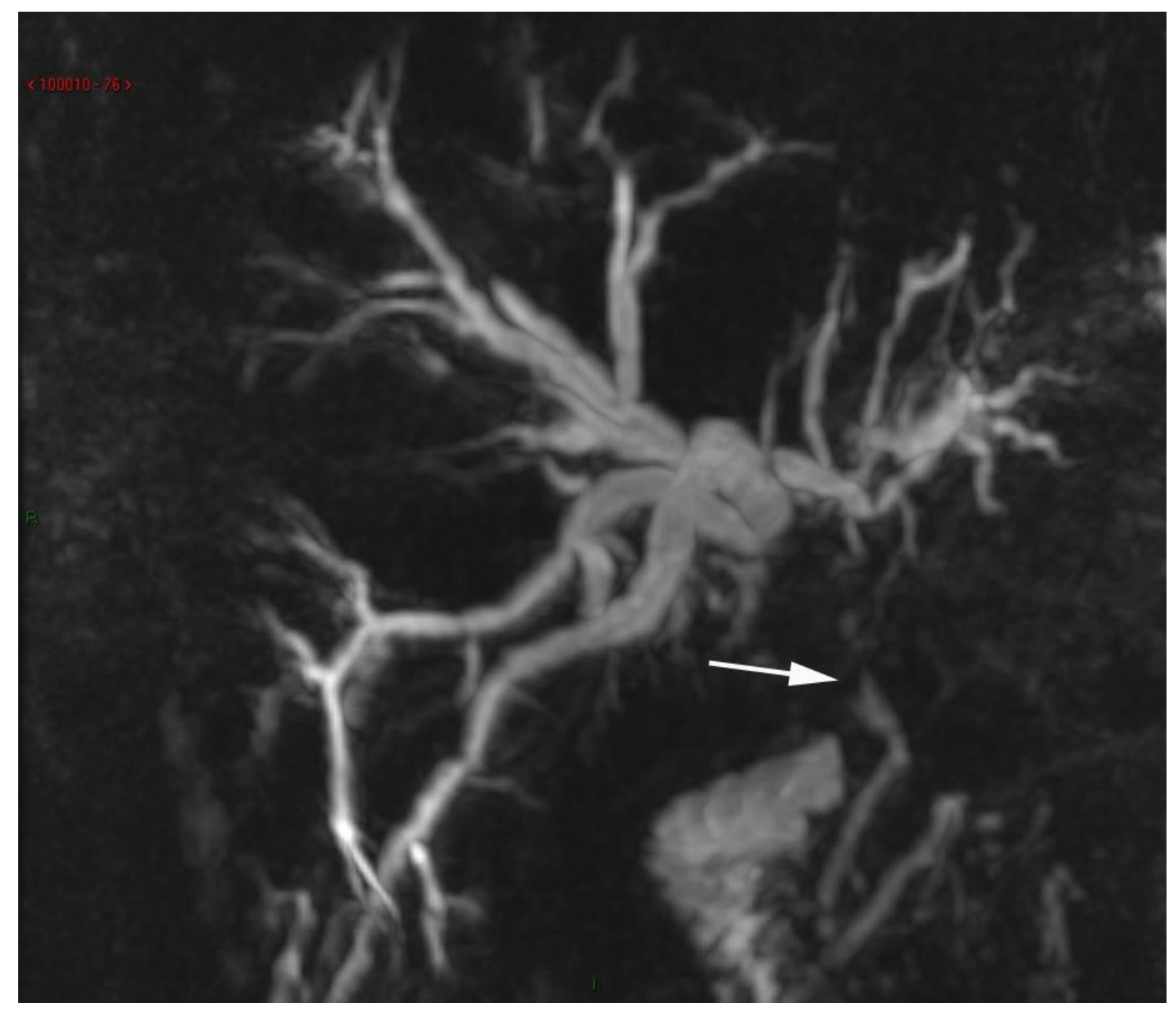

Fig. 1a 


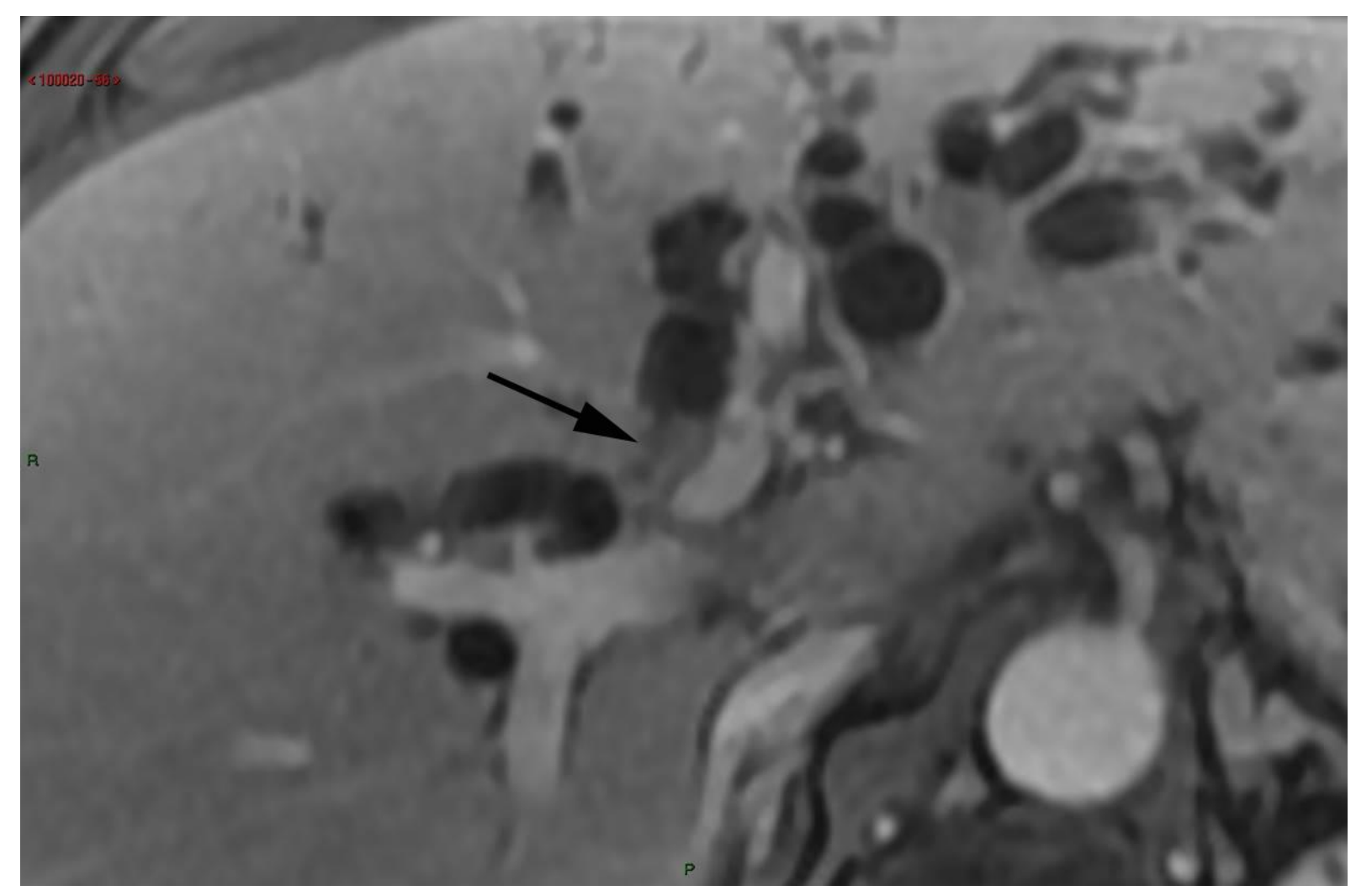

Fig. 1b 


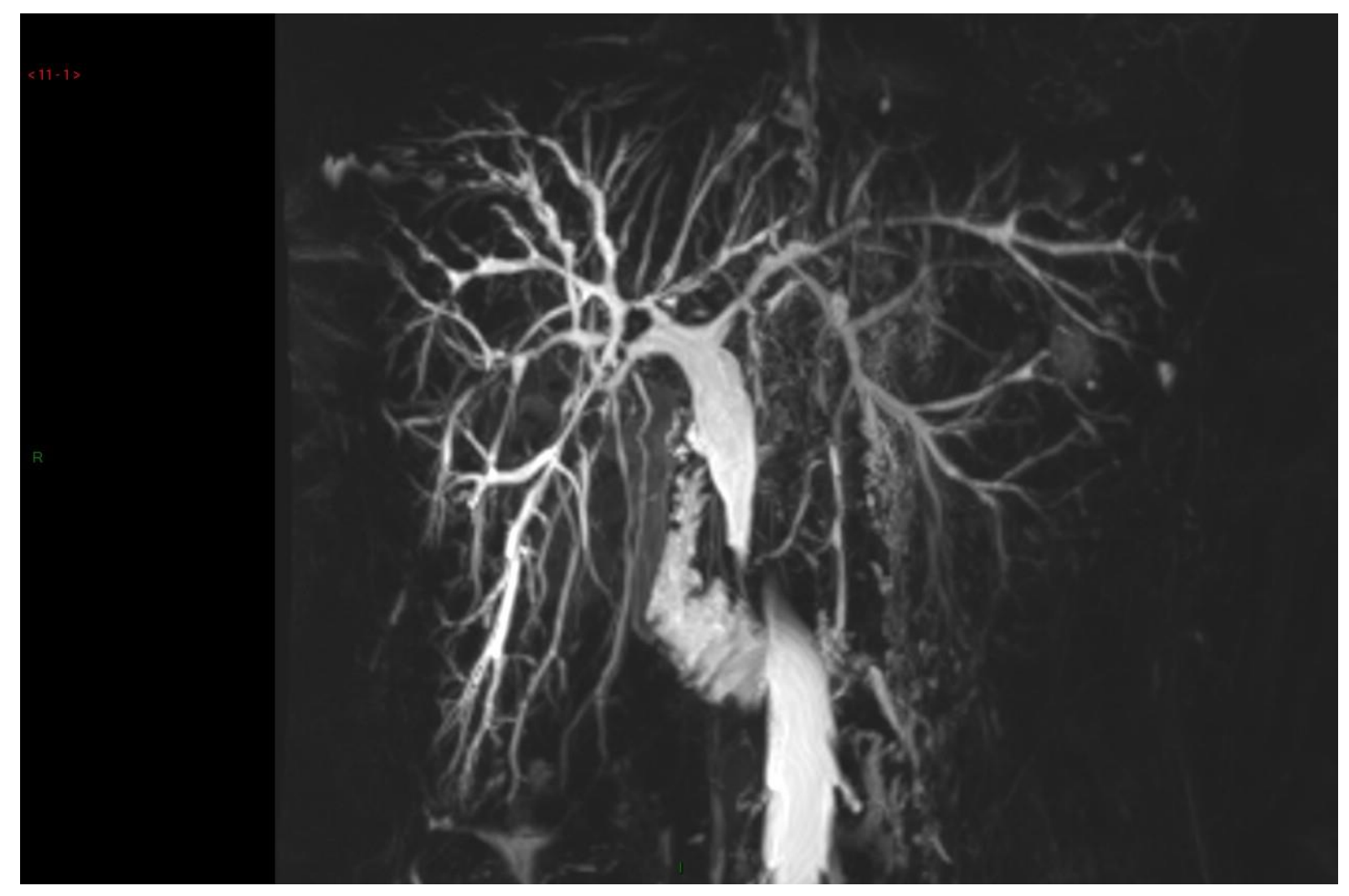

Figure 2a 


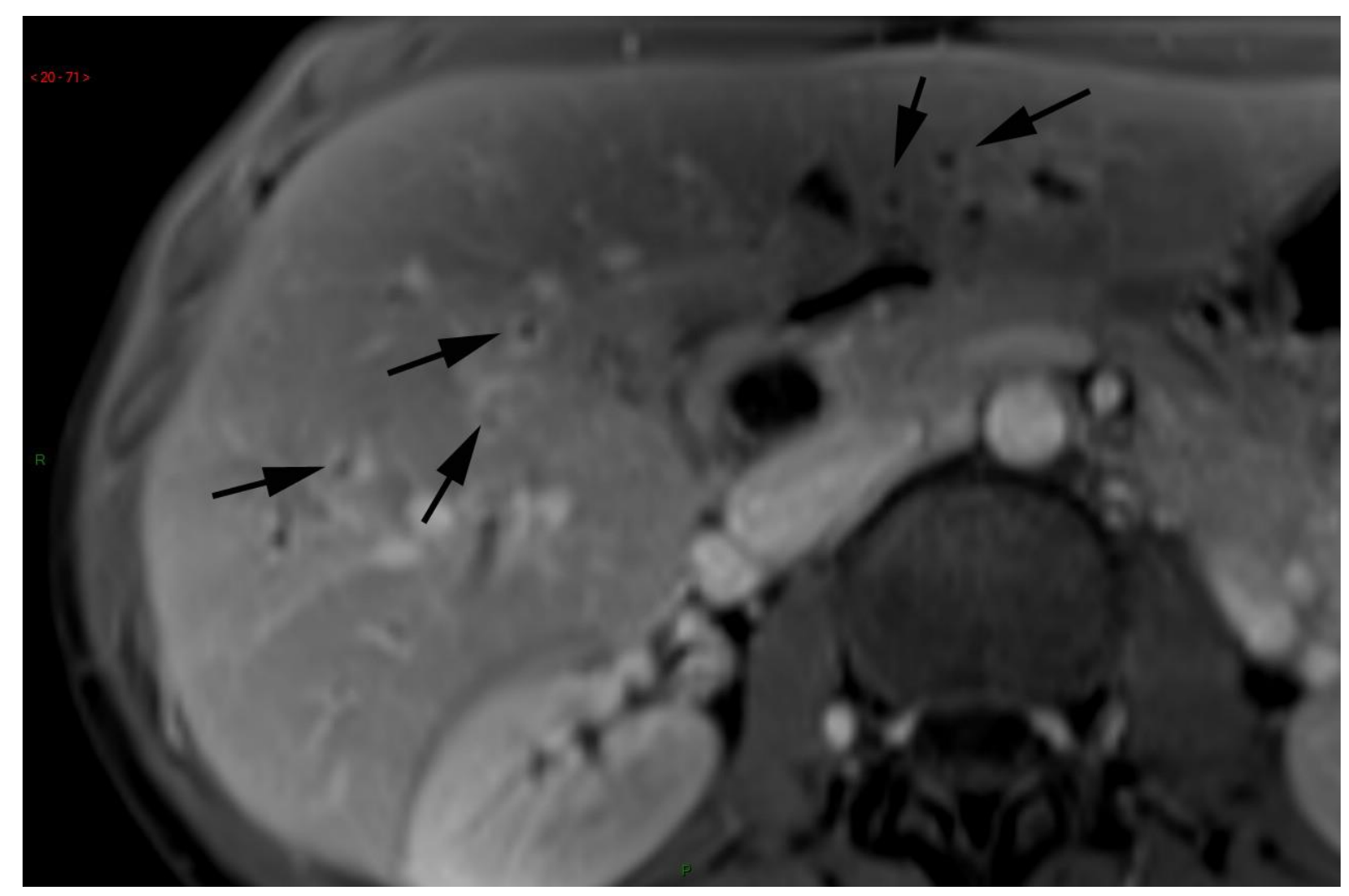

Figure $2 b$ 


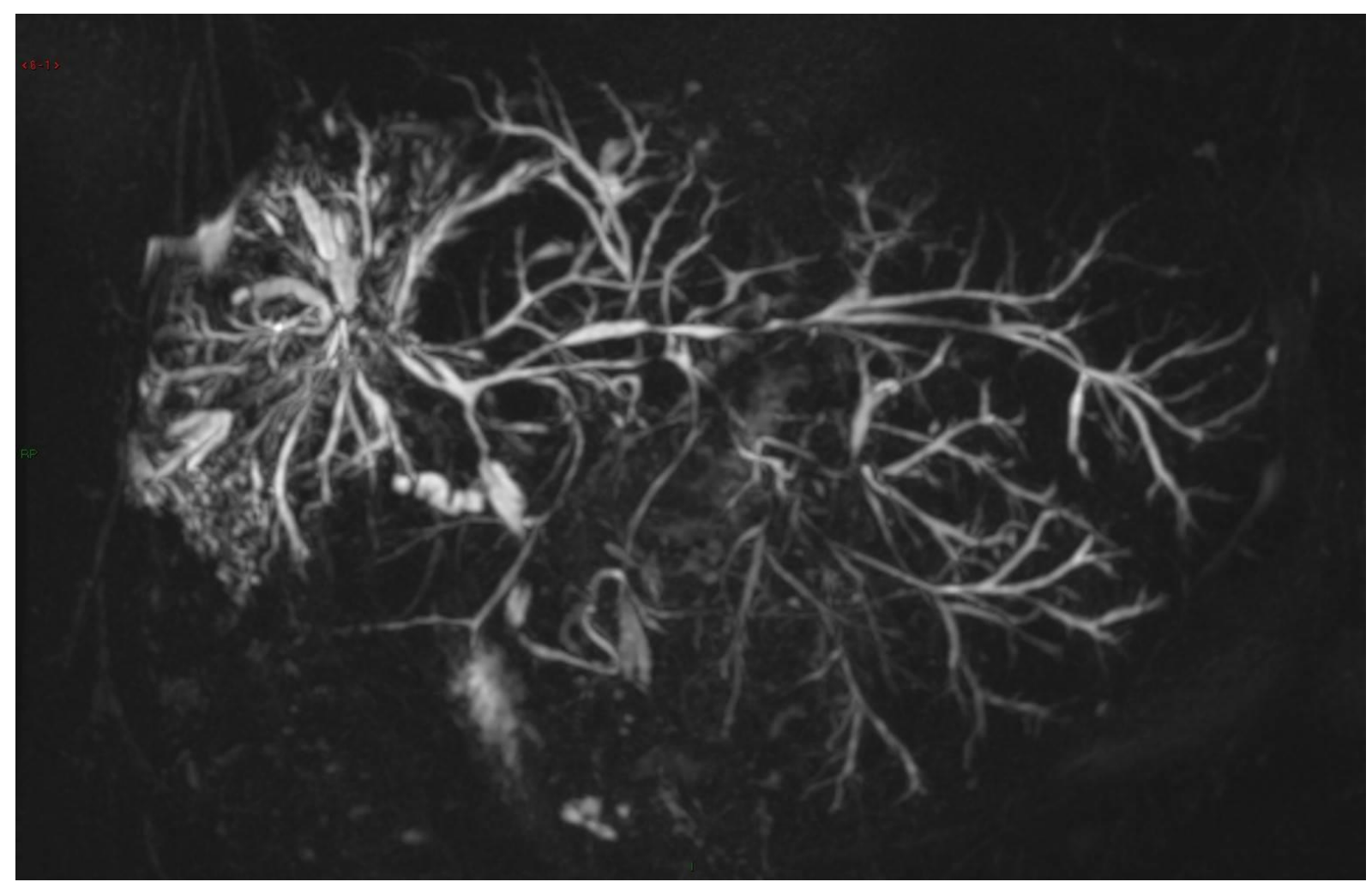

Figure $3 \mathrm{a}$ 


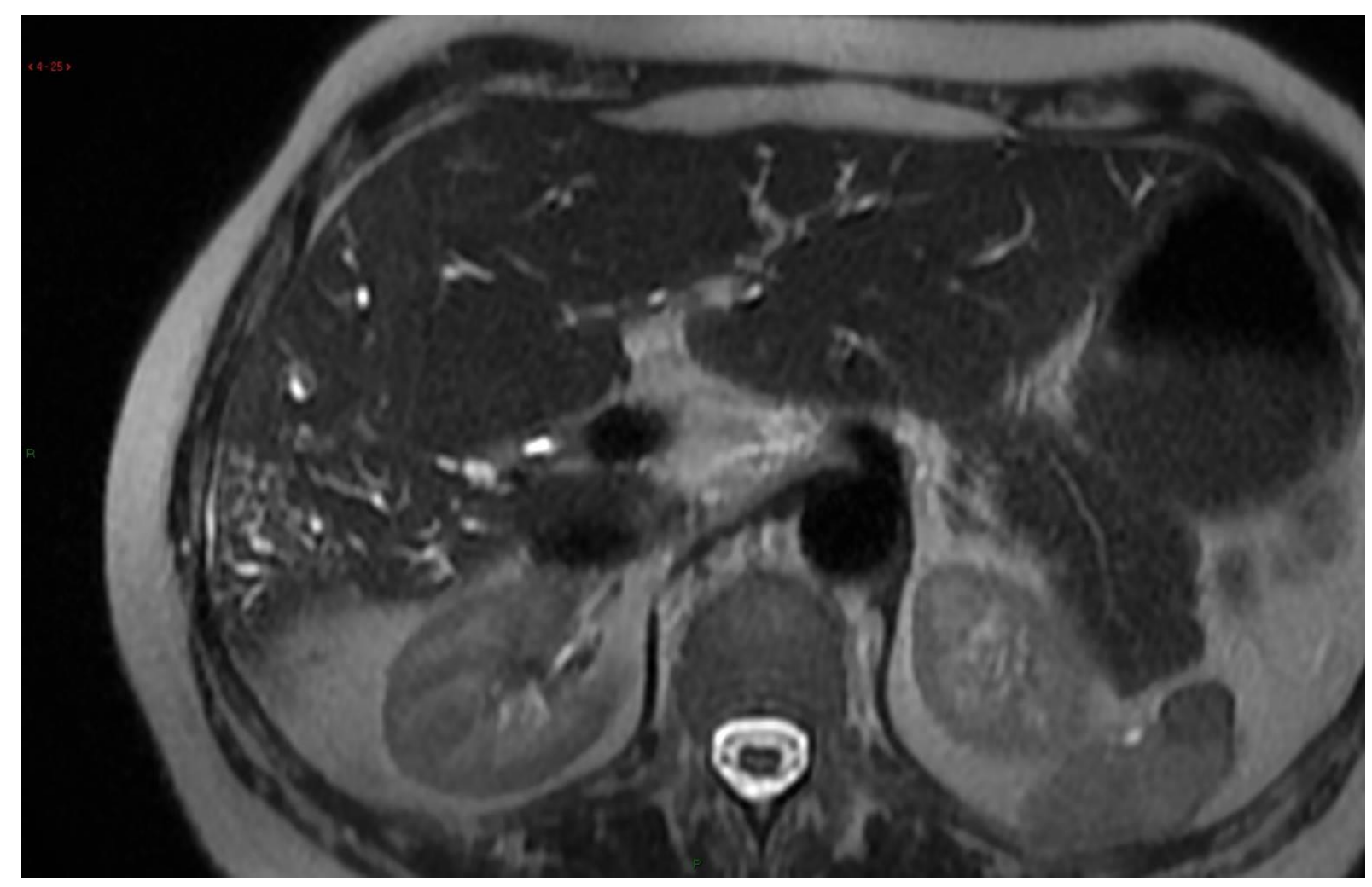

Figure $3 b$ 


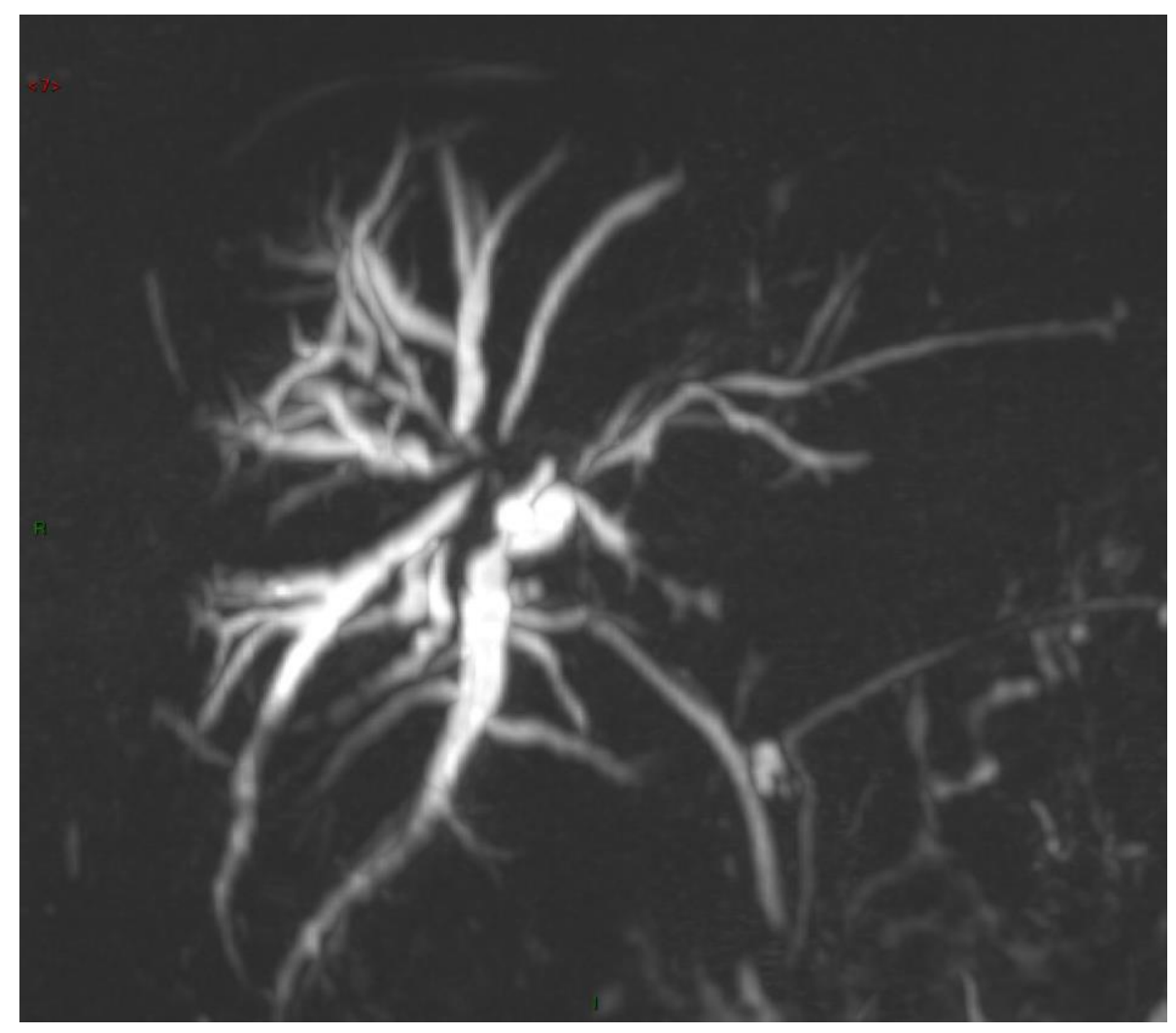

Figure 4a 


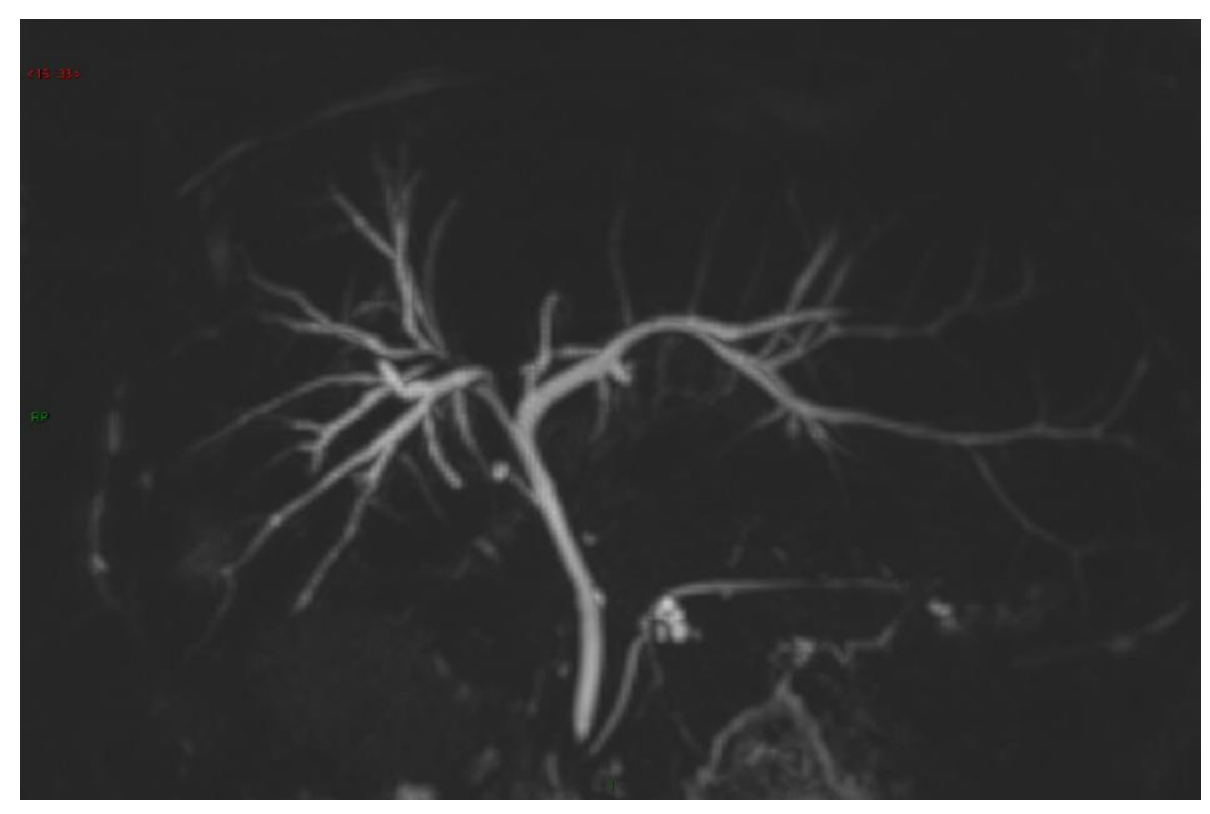

Figure $4 b$ 


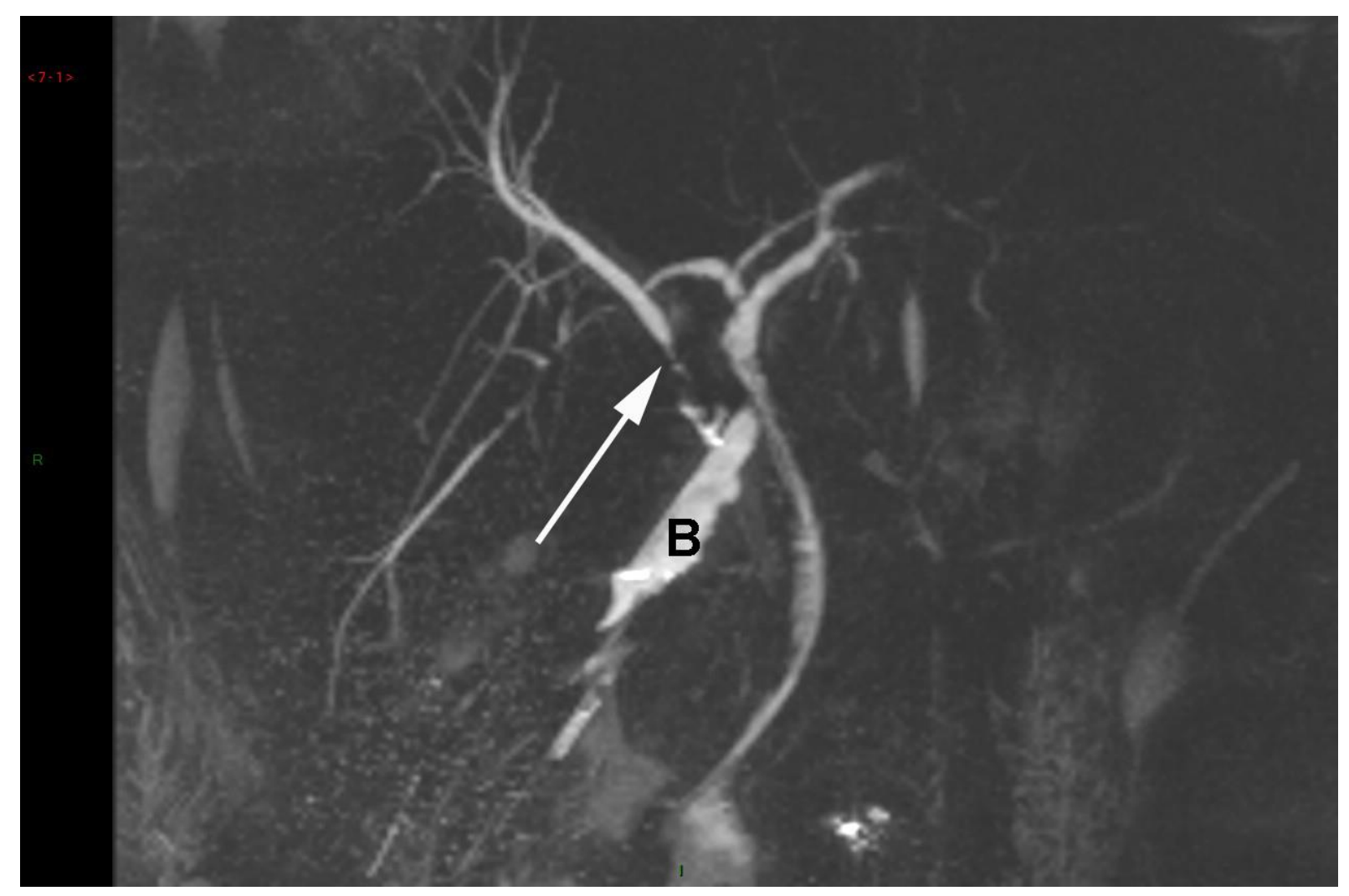

Figure 5a 


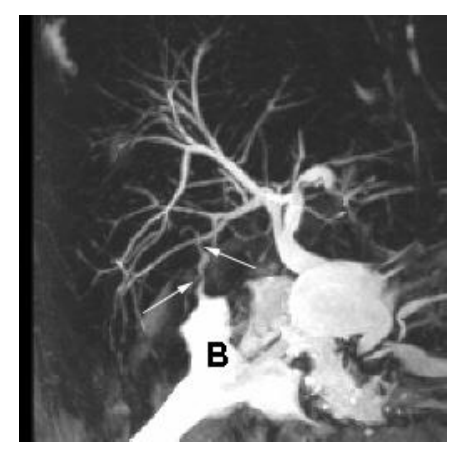

Figure $5 b$ 